Portland State University

PDXScholar

Winter 2014

\title{
Values Mapping with Latino Forest Users: Contributing to the Dialogue on Multiple Land Use Conflict Management
}

\author{
Kelly Biedenweg \\ Stanford University \\ Lee Cerveny \\ US Forest Service Pacific Northwest Research Station \\ Rebecca J. McLain \\ Portland State University, mclainrj@pdx.edu
}

Follow this and additional works at: https://pdxscholar.library.pdx.edu/iss_pub

Part of the Geographic Information Sciences Commons, and the Sustainability Commons Let us know how access to this document benefits you.

\section{Citation Details}

Kelly Biedenweg, Lee Cerveny, and Rebecca McLain (2014) Values Mapping with Latino Forest Users: Contributing to the Dialogue on Multiple Land Use Conflict Management. Practicing Anthropology: Winter 2014, Vol. 36, No. 1, pp. 33-37.

This Article is brought to you for free and open access. It has been accepted for inclusion in Institute for Sustainable Solutions Publications and Presentations by an authorized administrator of PDXScholar. Please contact us if we can make this document more accessible: pdxscholar@pdx.edu. 


\section{VALUES MAPPING WITH LATINO FOREST USERS: CONTRIBUTING TO THE DIALOGUE ON MULTIPLE LAND USE CONFLICT MANAGEMENT}

\author{
By Kelly Biedenweg, \\ Lee Cerveny, \\ and Rebecca McLain

\section{Introduction}

$\mathrm{V}$ alues mapping that represents how humans associate with natural environments is useful for several purposes, including recognizing and addressing different perceptions of natural resource ownership and management priorities, documenting traditional ecological knowledge, and spatially identifying the public's perception of economic and non-economic services provided by natural resources (McLain et al. 2013). The majority of this work has been conducted in developing countries and with disenfranchised communities, where participatory mapping associated with natural resource management is more widely practiced. As access to GIS technology has expanded, however, several projects have tested the benefits of values mapping for natural resource management decisions in industrialized countries (e.g., Brown 2005; Klain and Chan 2012). This article discusses one such effort: the use of spatial values mapping to incorporate the concerns of Latino forest users into federal and state policies on the Olympic Peninsula in Washington State.

In 2008, practicing anthropologists from the United States Forest Service Pacific Northwest Research Station (USFSPNWR) and the Institute for Culture and Ecology, a Portland-based research organization, designed the Human Ecology Mapping (HEM) Project. The project consisted of a series of workshops in which residents from the Olympic Peninsula mapped places they valued and activities they practiced throughout the peninsula. These workshops incorporated mapping as an interactive format for gathering what is often standard interview data. Qualitative responses were then carefully analyzed to understand the context of the geospatial responses. Workshop participants all resided on the Olympic Peninsula (6,432 square miles), the westernmost region of Washington State. The Olympic Mountains dominate the central portion of the peninsula and form a boreal rainforest that is highly valued for its biodiversity and tourism opportunities. Lands are managed by the Olympic National Park and Olympic National Forest as well as tribes, state agencies, and private owners. Home to 234,772 residents, the peninsula has shifted from a primarily timber harvesting economy to one based on tourism, non-timber forest products, shellfish harvest, commercial fishing, and logging. These economic shifts have been mirrored by demographic shifts, including an increase in the Latino population to 15 percent (State of Washington 2010).

The HEM team recognized that, despite this significant percentage, few Latinos participated in the mapping workshops. Consequently, the team collaborated with an organized group of Latino residents to incorporate Latino voices into the mapping effort using the principles of participatory action research. The Latino Mapping Project (heretofore "the Project") was funded by a Research in Underserved Communities grant from the USFS-PNWR to encourage research collaboration with a group that was historically underserved by land management agencies.

Based on initial discussions between the HEM team and the Latino group, the Project was designed to collect data from Latinos about their resource-based values and activities, while also allowing space for the discussion of conflicts and safety concerns. The group was particularly interested in bringing floral greens and shellfish harvesters to the table, as many Latinos work in those industries on the Olympic Peninsula (McLain and Lynch 2010). The impetus for using the mapping space to discuss conflicts and safety was the killing of a Latino harvester by a local hunter (Kitsap Sun 2010). Several months later, a Latino harvester drowned while attempting to escape Border Patrol officers who had been called in to assist with interpretation at a USFS checkpoint for harvesting permits (Turnbull and Daza 2011). Both deaths heightened the Latino group's interest in using the mapping effort to initiate dialogue between Latino harvesters, land managers, and law enforcement officers about safety, resource use, and civil rights issues. The Project also took place in the context of a major expansion in the United States Immigration and Customs Enforcement's (ICE) efforts to apprehend and deport undocumented workers. Thus, the goals of the Latino Mapping Project were to: (1) test values mapping as a tool for identifying land-use values with an immigrant population based in the United States, and (2) contribute to this underserved community's capacity to dialogue with land managers and law enforcement officials about perceived resource use conflicts, civil rights, and safety concerns.

\section{The Mapping Process}

The Latino Mapping Project occurred in two phases, each collaboratively planned during 12 meetings with the HEM team and the Latino group. The first phase focused on developing a Spanish-language mapping workshop that provided responses to the question "What places on the Olympic Peninsula are most important to you?" A total of 14 participants joined the workshop, including 11 floral greens harvesters and 5 shellfish harvesters 


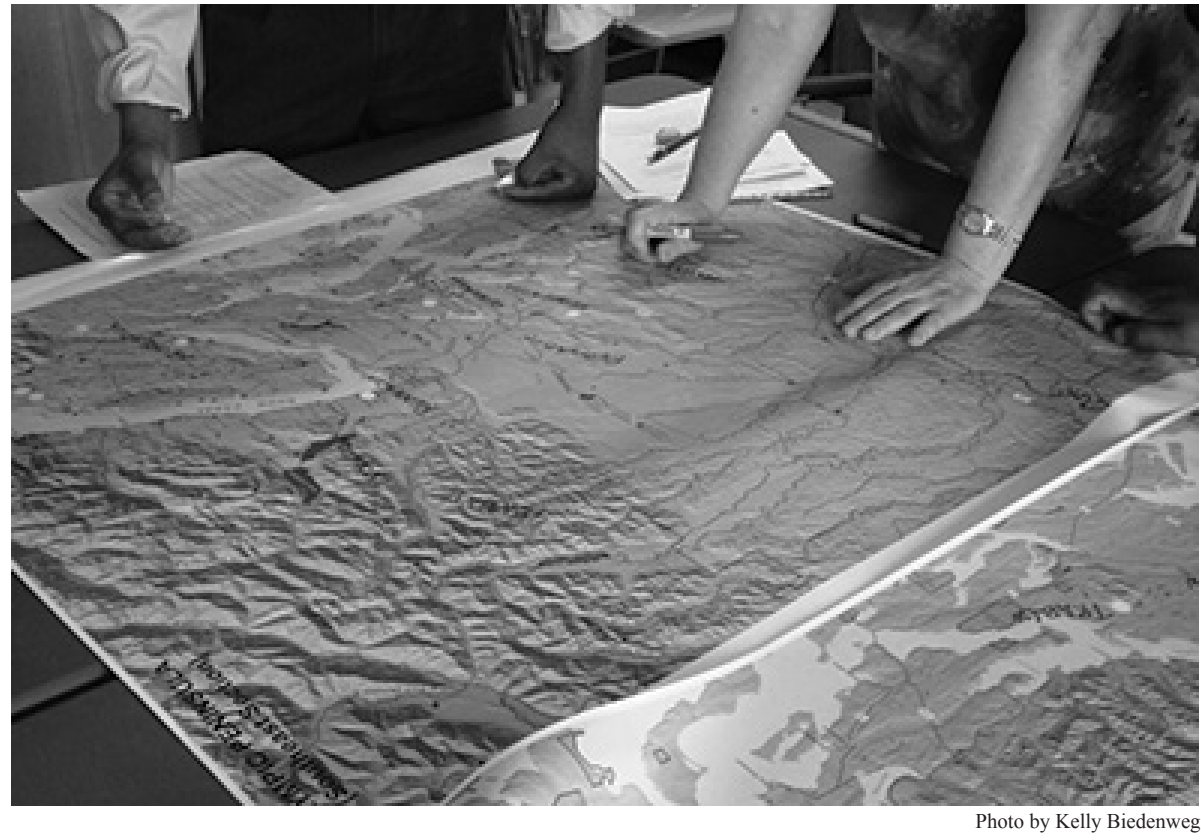

Figure 1. Participants Map Important Areas

(Figure 1). During planning meetings, the Latino group chose a method in which participants received six sticker dots that they could place on one of two maps, a 3'x3' enlargement of the nearby region (1:600,000 scale) and a 3'x3' version of the entire Olympic Peninsula (1:1,150,000 scale). To allow for more space and smaller discussions, participants were separated into three groups for the mapping, each facilitated by a bilingual volunteer. The volunteer made notes next to each sticker about the importance associated with that place. Groups discussed reasons why these areas were important and identified relevant issues or management concerns. Then, as a large group, participants discussed places that they would like to visit, but avoid, due to safety or other concerns. They also identified key issues on public and private lands affecting forest workers.

\section{Important Areas}

The majority of areas identified were important for either work (primarily harvesting shellfish, salal, or mushrooms) or recreation (i.e., family outings that might include a barbeque picnic, swimming, and walking in a beautiful area). One participant mentioned an area that was important for conservation. Most of the important areas were within a short distance of the Latino group's town (Figure 2).

\section{Land Use Concerns}

While mapping important areas, conversations emerged about the conflicts and concerns that workers encounter while in the forest. Workshop participants identified three critical concerns: immigration and law enforcement, forest safety, and compliance with forest regulations. These concerns are discussed in more depth below. In addition, participants brought up topics that were not elaborated upon, including: area closures (parks, beaches), the legitimacy of fine collections in the field, policies and regulations of floral greens corporations, trash dumping and littering, and decreased budgets for park maintenance.

\section{Immigration and Law Enforcement}

Both documented and undocumented Latino participants were concerned about being detained or treated unfairly by immigration and law enforcement officers while in forest areas. In some instances, legal workers with permits had been detained, affecting their ability to earn an income. Their concern about law enforcement included ICE, the USFS, and county sheriffs. Workshop participants suggested that when the USFS calls ICE to translate during harvesting permit checks, they are actually collaborating in the search for undocumented workers. They also described a specific section of road where they believed the sheriff's office, USFS, and ICE collaborated to check papers (driver's license, harvest permit, and work papers, respectively) at three different points along the road. The fear of being stopped by immigration or other law enforcement officers influenced where documented and undocumented Latinos felt they can safely work or recreate:

The number one reason we don't go places is because of immigration and police.... I would like to go to the beaches near Canada, around Forks, for recreation, but we can't because of the raids.

Participants also complained about being treated unfairly. One person described an incident when a sheriff blamed him for littering and forced him to pick the litter up:

\begin{abstract}
About three years ago near state land, I was parked in my truck and a sheriff arrived and he blamed me for some trash that wasn't minecigarette packet and McDonald's bags — and he said, "Pick up your trash,” and I said, "But, I'm just now getting here," and he said that if I didn't pick up the trash he would give me a ticket. He didn't realize that I wasn't the responsible person-I don't even smoke.
\end{abstract}

The ultimate concern about law enforcement stemmed from perceptions that the judicial system does not work properly and that law enforcement actions are carried out in ways that endanger people's lives. Two incidents were used to illustrate this point. First, participants described a recent case in 2010 when a hunter, who had shot a harvester in the forest, was acquitted of manslaughter charges:

[We'd like to] express our discontent that the hunter got off free 
when he shouldn't. Because for all of us it was an injustice - because the guilty man was not punished.

Participants expressed concern that the court decision minimized the danger forest workers face and condoned irresponsible hunting. The acquittal suggested a lack of closure to this tragic incident and symbolized the unresolved safety issues. Second, residents worried that raids by ICE could result in deaths similar to when an undocumented worker was fleeing officials and fell to his death in the river:

It's already happened that someone threw himself into the river in Forks because he thought he was being chased. We hope that never has to happen again.

\section{Forest Safety}

Workshop participants expressed concern about irresponsible hunters and target shooters on public and private forestlands. Although agencies or landowners often post signs that firearms are prohibited in certain areas, hunters and target shooters sometimes disregard rules. Several incidents were described where target practice or hunting occurred in areas where people harvest forest products. Participants recognized that not all hunters behave unsafely and associated this behavior with youth or people drinking alcohol:

There are places that we can go, but we worry about because during hunting season the hunters are there all the time. The problem is that, not all, but some are irresponsible. Some drink... and the other thing are those who target practice. Even though the State's gates say that firearms are prohibited, they don't respect it. They go into the area. Then they begin to shoot blanks and they don't know or they don't want to respect that people are in front of them working and they don't look for a safe place to practice. ... This is what concerns the harvesters: that a bullet could go to where we are and kill us.

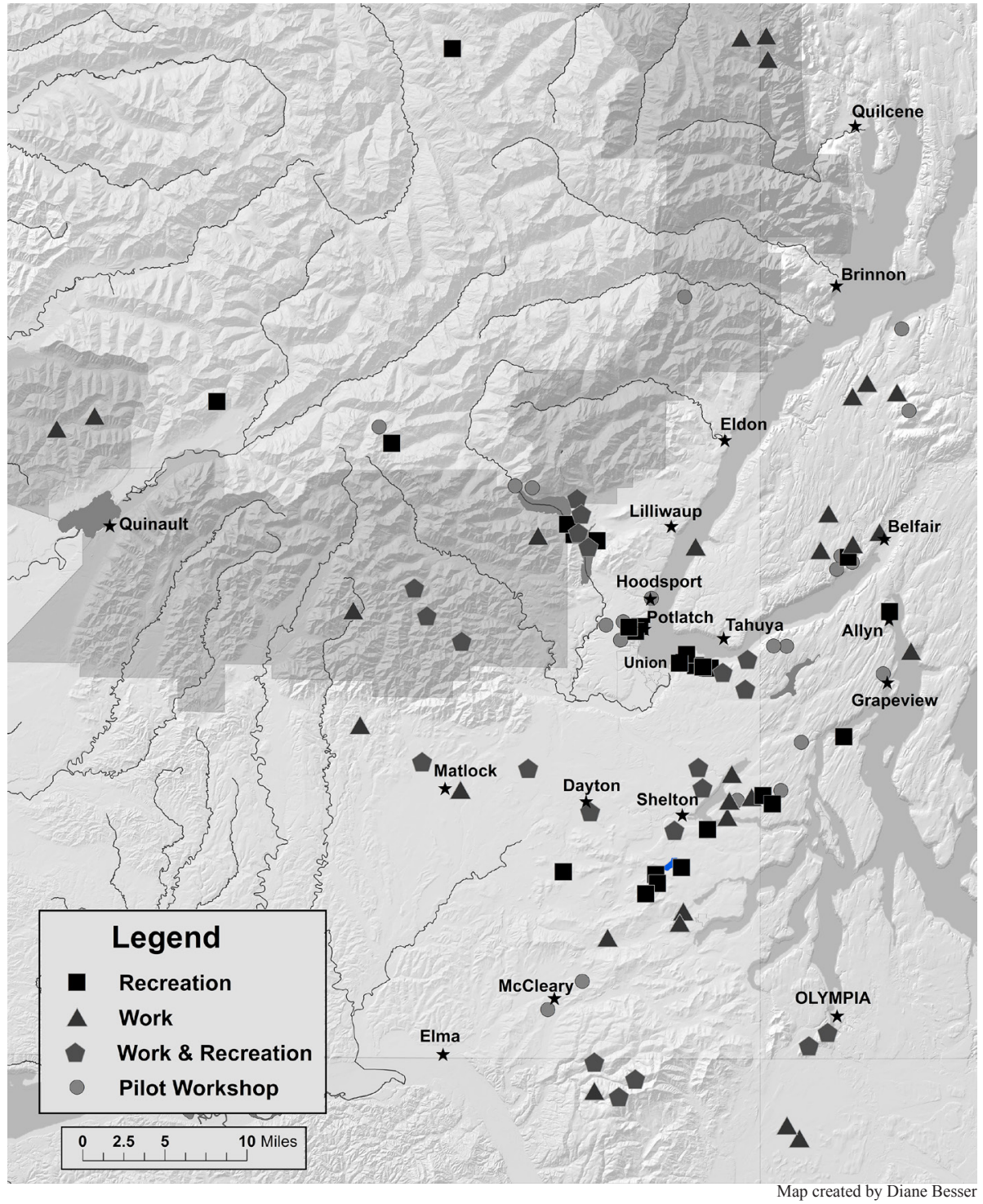

Figure 2. Compiled Location of Stickers, Categorized by Primary Value Type

Participants discussed the need for harvesters to wear orange vests while in the forest and to find other ways to highlight their presence (e.g., placing signs that harvesting is underway, distributing information to hunters about brush-picking practices, and communicating with brushpickers about hunting seasons when they obtain permits). They also expressed a desire to share concerns directly with hunters.

\section{Compliance with Harvest Regulations}

Participants described problems with other harvesters who disregard harvesting rules, particularly going outside their designated harvesting areas and littering.
Some landowners had made attempts to communicate and enforce the rules, but others had not. Part of the blame was placed on harvesters themselves for disregarding rules, while others blamed landowners who failed to educate, enforce rules, or confirm the presence of harvestable products in the area for which the permit was valid:

The State gives out maps... and also the areas are marked in the field...one knows where their area is. But people, sometimes, out of necessity since they can't find any product and they've already 
paid their permit, these people have to make money so they go to areas that they don't have a permit for.... If the company was more responsible, it would make sure that people don't leave their designated areas....

The brush harvesting companies could do more because, [in one example], they give permits, and they don't care if people go outside their areas. Other companies take care of their workers. They talk with the crew boss and ask him to try to prevent trash and make sure people don't go outside their areas and that if they go outside they will take the permit away ... and the workers are more aware [than other places].

\section{The Dialogue}

For the second phase, the Latino group and HEM team invited Latino harvesters, regional land managers, and law enforcement officers to a facilitated meeting to discuss forest safety and permitting regulations. The meeting was suggested by participants during the mapping workshop as a way to address their concerns and build ties between the Latino community and local land managers. Participants included eight Latino citizens; a representative from Rayonier Corporation; and law enforcement and representatives from federal, state, and local agencies, including: the USFS, Washington Department of Natural Resources (WADNR), Washington Department of Fish and Wildlife (WADFW), and the Mason County Sheriff's Office. The meeting was conducted in Spanish with simultaneous English translation shared by two translators. Two agency representatives were also native Spanish speakers.

The meeting began with a presentation in Spanish led by the Latino group that they had prepared over the course of five internal meetings after the mapping workshop. The presentation described the group's perspectives about the safety issues they currently face in the forest, perceived causes of those issues, and ideas for potential solutions. Then, the group identified three main topics on which they had questions for the land managers and law enforcement officers: hunting rules, emergency procedures, and general suggestions to improve safety. An open discussion followed with harvesters and agency representatives sharing ideas. The meeting concluded with participants sharing contact information and delicious tamales.

\section{Agency Response and Collaborations Built}

Agency representatives responded enthusiastically to the opportunity to learn from and share with the Latino community. They answered questions about hunting rules (where hunting and target shooting are permitted), hunter training (whether they receive information about forest harvesters), hunting seasons, and what to do in case of an emergency. They provided suggestions for staying safe while in the forest, including wearing reflective orange vests, making noise, purchasing $\mathrm{CB}$ radios, knowing their land tenure and harvest-area boundaries, staying aware of active timber harvesting sites, and driving with appropriate lighting to avoid accidents with timber trucks. Other jointly developed ideas for enhancing safety in the woods included: radio spots during high-risk seasons, pamphlets for both hunters and harvesters, signs that could be hung on trees, and a flag that could be placed where a harvester enters the forest, much like those used to indicate scuba diving spots.

Additionally, agency representatives discussed opportunities for collaboration. The WADNR in particular was pleased to discuss ideas for reaching out to underserved communities. During the meeting, they committed to and have since completed the development of safety pamphlets and brochures in Spanish that will be distributed to harvesters upon receiving their harvesting permits. The concerns discussed at the meeting provided the content for these educational materials, and the contacts established provided a mechanism for seeking review of the materials. Representatives from USFS were similarly pleased to establish relationships with the Latino harvester community as they could provide feedback on prototype Spanishlanguage pamphlets about special forest products. A representative also requested their contact information to facilitate future communication about new materials, laws, or emergencies that could affect Latino forest users. Lastly, during three post-dialogue meetings between the HEM team and the Latino group, the remaining funds from the Latino Project were dedicated to purchasing reflective vests for distribution and additional copies of the WADNR materials.

\section{Discussion}

Values mapping is a promising tool that integrates anthropological and geographic methods to address pressing needs in natural resource management. The Latino Mapping Project explored methods for incorporating underserved United Statesbased populations in this process and observed how it could stimulate dialogue to address land-use concerns. The most crucial element to the Project's success was the development of trust, developed over a dozen meetings between the HEM researchers and Latino residents. These meetings focused on empowering the Latino group to take ownership of the process and were possible because of the dedication of a local English as a Second Language (ESL) educator who helped link the two groups. The execution of the mapping exercise expanded that trust to other Latino participants and spurred a dialogue between Latino harvesters, land managers, and law enforcement officers about resource use and safety in the woods. Additional factors that enhanced trust and the Project's success included: modifying mapping methods to use sticker dots based on the Latino group's preference, selecting neutral locations where many Latino residents regularly visit for meetings, having the primary HEM team representative fluent in Spanish and facilitating all meetings in Spanish, and providing local food at meetings.

As mentioned in the introduction, this opportunity for dialogue was timely. A complaint of discrimination was filed with the United States Department of Agriculture's Office of 
the Assistant Secretary for Civil Rights (OSCAR) precisely as we were designing the mapping process (USDA 2012). The complainant argued that the USFS's reliance on Border Patrol agents to provide interpretive services in a non-emergency situation exposed a person with limited English proficiency to heightened risk of harm, thereby limiting access to the USFS's services and programs. Two months after the dialogue meeting, OSCAR issued an administrative decision in favor of the complainant. As a result, the USFS has been directed to provide meaningful access to its services and programs to individuals with limited English proficiency. The success of the Latino Mapping Project suggests that providing long-term support for collaborative values mapping with underserved communities is a promising means by which the agency can develop such capacity.

\section{Acknowledgements}

The authors extend their gratitude to Inmigrantes Unidos (IU) for their time and effort in preparing these meetings. In particular, we thank Jenny Blumenstein, our primary liaison to the IU group. We also thank our volunteer translators (Melissa Poe, Jennifer Arnold, Graciela Etchart, and Glenna Campbell) and our volunteer workshop assistant (Lee Greer). We appreciate the time and responsiveness of representatives from the United States Forest Service, Washington Department of Natural Resources, Washington Department of Fish and Wildlife, Rayonier, and Mason County Sheriff's Office. St. David's Episcopal Church and the CHOICE school of Shelton, Washington allowed us to meet in their spaces. Finally, we thank Diane Besser for digitizing the mapping data and creating the map of meaningful places. The project was funded by a United States Forest Service Pacific Northwest Research Station Research for Underserved Communities Grant.

\section{References Cited}

Brown, Greg

2005 Mapping Spatial Attributes in Survey Research for Natural
Resource Management: Methods and Applications. Society and Natural Resources 18(1):1-23.

Kitsap Sun, Staff

2010 Investigation Continues in Death of a Brush Picker. URL:<http://www.kitsapsun.com/ news/2010/sep/30/investigationcontinues-in-death-of-brushpicker/\#axzz2nYt22VZ3> (September 30, 2012).

Klain, Sarah, and Kai Chan

2012 Navigating Coastal Values: Participatory Mapping of Ecosystem Services for Spatial Planning. Ecological Economics 82(C):104-113.

McLain, Rebecca, Melissa Poe, Kelly Biedenweg, Lee Cerveny, Diane Besser, and Dale Blahna

2013 Making Sense of Human Ecology Mapping: An Overview of Approaches to Integrating Socio-Spatial Data into Environmental Planning. Human Ecology 41(5):651-655.

McLain, Rebecca, and Kathryn Lynch 2010 Managing Floral Greens in a Globalized Economy: Resource Tenure, Labour Relations and Immigration Policy in the Pacific Northwest, USA. In Wild Product Governance: Finding Policies that Work for Non-Timber Forest Products. Sarah Laird, Rebecca McLain, and Rachel Wynberg, eds. Pp. 265-286. London, United Kingdom: Earthscan.

State of Washington

2010 Population by Race and Hispanic or Latino Origin for all ages and for 18 years or over. URL: $<$ https://data.wa.gov/Demographics/WAOFM-2012-LegislativeDistricts-Table-2-Census-20/di4yk8za> (November 6, 2013).

Turnbull, Lornet, and Roberto Daza 2011 Climate of Fear Grips Forks Illegal Immigrants. URL: $<$ http:// seattletimes.com/html/localnews/2015435439_forks27m.html> (September 29, 2012).
United States Department of Agriculture, Office of the Assistant Secretary for Civil Rights (USDA)

2012 Final Agency Decision on Program Complaint No. FS-115171. April 28. URL: $<$ http:// nwirp.org/Documents/PressReleases/DecisionOfOASCRUSDAreCivilRightsComplaintREDACTEDforRelease.pdf> (September 29, 2012).

\section{Kelly Biedenweg}

(kbied@uw.edu) is a social scientist with the Natural Capital Project at Stanford's Woods Institute for

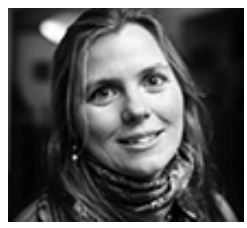
the Environment, Lead Social Scientist at the Puget Sound Institute, and Visiting Scientist at the United States Forest Service Pacific Northwest Research Station. She explores metrics for social and cultural values associated with natural resources and finds ways to incorporate such data into natural resource decision making. Dr. Biedenweg is fluent in Spanish.

Lee Cerveny(lcerveny@ fs.fed.us) is a research social scientist with the United States Forest Service Pacific Northwest Research Station in Seattle, Washington.

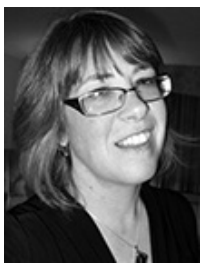

Her research focuses on sociospatial mapping for use in land management, emerging forms of natural resource governance, and human-nature interactions in the wildland-urban interface.

\section{Rebecca McLain} (mclainrj@pdx.edu) is a research faculty member at the Institute for Sustainable Solutions at Portland State University. She

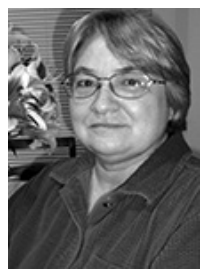
studies participatory governance structures, environmental justice, and the links between resource tenure and environmental management practices. 